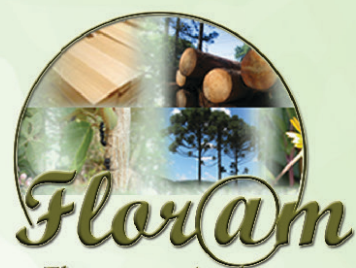

Floresta e Ambiente
Floresta e Ambiente 2019; 26(Spec No 2): e20180423 https://doi.org/10.1590/2179-8087.042318

ISSN 2179-8087 (online)

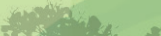

Original Article

Wood Science and Technology

\title{
Evaluation of Rice Bran as a Supplement for Production of Bioethanol by Saccharomyces cerevisiae
}

\author{
Victor Rezende Moreira ${ }^{1}$ (D), Yuri Abner Rocha Lebron ${ }^{1}$, Sara Jenifer Freire ${ }^{1}$, \\ Fernanda Palladino ${ }^{1,2}$, Lucilaine Valéria de Souza Santos ${ }^{1}$, Raquel Sampaio Jacob ${ }^{1}$ \\ ${ }^{1}$ Pontifícia Universidade Católica de Minas Gerais - PUC-MG, Belo Horizonte/MG, Brasil \\ ${ }^{2}$ Instituto de Ciências Biológicas, Universidade Federal de Minas Gerais - UFMG, Belo Horizonte/MG, Brasil
}

\begin{abstract}
There is an increase in researches to create alternative fuels through the use of biomass and agroindustrial lignocellulosic residues. The present study proposes the use of rice bran as source of energy with the potential to enhance bioethanol production. Using different concentrations of cells $\left(1-5\right.$ g.L. $\left.\mathrm{L}^{-1}\right)$ and rice bran (2.5-7.5 g.L. $\left.\mathrm{L}^{-1}\right)$ with Saccharomyces cerevisiae, a factorial design $2^{2}$ was carried out. The nutrient source provided by rice bran affects the substrate conversion in product $\left(Y_{p / s}\right)$ response in a quadratic form, but its linear form showed no significant effect $(\alpha=0.05)$. When it comes to means, the best results were obtained for $12 \mathrm{~h}$ and for fermentation medium 2 (23.320 g. $\mathrm{L}^{-1}$ of ethanol), which contained the highest rice bran concentration and the lowest initial cell concentration. Medium 3, consisting of 2.5 g.L.- $\mathrm{L}^{-1}$ and $5 \mathrm{~g} . \mathrm{L}^{-1}$ of rice bran and cells, respectively, showed the lowest $K_{s}(4.434$ g.L.- $)$.
\end{abstract}

Keywords: biofuel, fermentation, ethanol production, dry weight curve, glucose. 


\section{INTRODUCTION}

Minimizing the use of fossil fuels is a great desire of modern society, both to reduce pollution and to find new alternatives for renewable fuels. Among the numerous alternative sources of energy, those from lignocellulosic biomass has been investigated, especially for its potential to produce biofuels (Sharma et al., 2017). The global biofuel utilization accounted for $10 \%$ of the world energy consumption and $80 \%$ of the total renewable energy production (Guo et al., 2015).

In this context, the bioethanol stands out as a renewable source through the use of biomass as raw material. It is considered a renewable and sustainable liquid fuel that offers several advantages over conventional fossil fuels such as higher octane number (108), broader flammability limits, higher flame speeds and increased heats of vaporization (Arenas-Cárdenas et al., 2017). It is also less toxic, readily biodegradable and produces lesser airborne pollutants, when compared to conventional fuels such as gasoline (Azhar et al., 2017). The main way of bioethanol production is trough fermentation process by microorganisms such as yeasts.

For the alcoholic fermentation, the most popular microorganism used is Saccharomyces cerevisiae yeast, as it rapidly converts sugars into alcohol, organic acids and carbon dioxide, and is tolerant to high ethanol concentrations (Mohd Azhar et al., 2017). Moreover, nutrient supplementation in the fermentation stage optimizes yeast growth and increases ethanol production (Zabed et al., 2017). One possible supplement for the fermentation process is the rice bran, a by-product of the rice processing industry composed by $15 \%$ proteins and $47 \%$ carbohydrates, possible fermentable sugars, justifying the high interest in their use in processes such as fermentation (Favaro et al., 2017).

Based on these considerations, the present work aimed to evaluate the influence of rice bran and initial cell concentration in the fermentation process using Saccharomyces cerevisiae. This work also aimed to define the kinetic parameters using the Monod's model applying the linearized form of Hanes-Woolf.

\section{MATERIALS AND METHODS}

\subsection{Preparation of rice bran extract}

For each liter of ultrapure water (Thermo Scientific Smart2Pure), $200 \mathrm{~g}$ of rice bran was added, and the mixture autoclaved at $111^{\circ} \mathrm{C}$ for $15 \mathrm{~min}$ (Prismatec CS-75).
The mixture was then centrifuged (FANEM Excelsa 2206) at $3000 \mathrm{rpm}$ for $15 \mathrm{~min}$ and, while still hot, the supernatant was separated and reserved in sterile Erlenmeyer's flasks.

\subsection{Microorganism and culture conditions}

In the preparation of the inoculum for fermentation, the yeast Saccharomyces cerevisiae, isolated from a brewing process, was grown in a $125-\mathrm{mL}$ Erlenmeyer containing $50 \mathrm{~mL}$ of medium ( $40 \mathrm{~g} . \mathrm{L}^{-1}$ of glucose, $10 \mathrm{~g} . \mathrm{L}^{-1}$ of rice bran, $2 \mathrm{~g} . \mathrm{L}^{-1}$ yeast extract, $3 \mathrm{~g} . \mathrm{L}^{-1}$ of peptone and $0.1 \mathrm{~g} . \mathrm{L}^{-1}$ of calcium chloride). After $24 \mathrm{~h}$, the solution was centrifuged at $2000 \mathrm{rpm}$ for $15 \mathrm{~min}$, the supernatant was withdrawn, and the cells resuspended for further addition to the fermentative medium.

\subsection{Dry weight curve}

To monitor cell growth, a dry weight curve was prepared by cultivating the Saccharomyces cerevisiae cells in a 500-mL Erlenmeyer flask containing $200 \mathrm{~mL}$ of medium (40 g.L. $\mathrm{L}^{-1}$ of glucose, 10 g.L. $\mathrm{L}^{-1}$ of rice bran, 2 g.L. $\mathrm{L}^{-1}$ of yeast extract, 3 g.L. $\mathrm{L}^{-1}$ of peptone and $0.1 \mathrm{~g} . \mathrm{L}^{-1}$ of calcium chloride). This solution was then autoclaved and cooled. The incubation was carried out under agitation (200 rpm) using a shaker (Marconi MA139/CFT) at $30{ }^{\circ} \mathrm{C}$ for $24 \mathrm{~h}$.

An aliquot of $5 \mathrm{~mL}$, in duplicate, of each Erlenmeyer was collected and vacuum filtered in a cellulose acetate membrane (Sartorius) with $0.22 \mu \mathrm{m}$ and diameter $13 \mathrm{~mm}$, washed with saline solution $0.38 \% \mathrm{w} / \mathrm{v} \mathrm{NaCl}$. The membranes were weighed to determine the retained biomass. Finally, the membranes were placed in the oven at $60{ }^{\circ} \mathrm{C}$ and weighed every 24 hours until the value was stabilized.

In a $15-\mathrm{mL}$ falcon tube $10 \mathrm{~mL}$ of the inoculum was added and centrifuged for $15 \mathrm{~min}$ at $3000 \mathrm{rpm}$. The supernatant was discarded and the remaining material resuspended with $10 \mathrm{~mL}$ of saline solution in the vortex $\left(\mathrm{KASVI}_{\text {basic }} \mathrm{K} 45-2810\right)$. The resulting solution was diluted to different concentrations for further analysis on the UV-Vis spectrophotometer (Shimadzu UV 3600). With the respective concentrations, the absorbance was determined using a wavelength of $620 \mathrm{~nm}$. Given the absorbance values, a calibration curve was constructed by correlating the concentration with the sample absorbance. 


\subsection{Experimental design}

To evaluate the influence of the factors in the fermentation process, a simple factorial design $\left(2^{2}\right)$ with two factors, concentration of rice bran and cell concentration, and two central points were used. The experiments were defined according to Table 1 .

Statistical analysis was performed using the Statsoft Statistica v13.2 program, using the experiment analysis tool with a level of significance $\alpha=0.05$.

\subsection{Batch fermentation}

In a $125-\mathrm{mL}$ Erlenmeyer flask, $50 \mathrm{~mL}$ of the fermentation medium was prepared ( 40 g. $\mathrm{L}^{-1}$ of glucose, 1 g. $\mathrm{L}^{-1}$ of calcium chloride, rice bran extract and cell concentration according to the experimental design). The temperature was maintained at $30 \pm 2{ }^{\circ} \mathrm{C}$, under constant stirring of $200 \mathrm{rpm}$, for 72 hours in a shaker. Aliquots of the system were collected at the regular intervals of 12 hours.

Once collected, the absorbance was measured and the aliquots were centrifuged at $2000 \mathrm{rpm}$ for $15 \mathrm{~min}$, reserving the supernatant for further analysis in high performance liquid chromatography (Shimadzu LC-20A Prominence).

\subsection{Kinetics of fermentative process}

The kinetic study of the process correlates the formation of the product of interest with the nutrients consumption. Since ethanol formation cannot occur without the presence of cells, it is expected that the microorganism growth and the product formation are closely related (Papapetridis et al., 2018). Among the most used mathematical models is the equation developed by Monod (1949), which describes the effect of limiting growth as a function of the specific growth rate. For the model in question, the cell growth rate can be expressed according to Equation 1 .

$\frac{d X}{d t}=\frac{\mu_{\max } S}{K_{s}+S} X$

In which $X$ (g. $\left.\mathrm{L}^{-1}\right)$ corresponds to the cellular concentration, $S$ (g. $\mathrm{L}^{-1}$ ) to the substrate concentration, $K_{s}\left(\mathrm{~g} . \mathrm{L}^{-1}\right)$ is the constant of Monod and $\mu_{\max }\left(\mathrm{h}^{-1}\right)$ is the specific rate of maximum growth. The Monod's constant is the limiting nutrient concentration for which the growth rate is half the maximum growth rate and represents the organism affinity for the nutrient. Both the value of $K_{s}$ and $\mu_{\max }$ depend on the microorganism, limiting nutrient, fermentation medium and factors such as temperature and $\mathrm{pH}$ (Lerkkasemsan \& Lee, 2018).

For cases where the substrate concentration is much higher, it is more convenient to consider the Hanes-Woolf form of the Monod's equation. For this mathematical model, the cell growth rate is related to the substrate concentration as described by Equation 2 (Fogler, 2009).

$\frac{C_{c}}{d X}=\frac{K_{s}}{\mu_{\max }} \frac{1}{C s}+\frac{1}{\mu_{\max }}$

The parameters $\mu_{\max }$ and $K_{s}$ can be obtained from the linear adjustment between the ratio of cell concentration $\left(C_{c}\right)$ and cell growth $(d X / d t)$ versus the inverse of the substrate concentration $(C s)$, being associated with the linear and angular coefficient of the obtained plot, respectively (Fogler, 2009).

Table 1. Concentration of rice bran extract and cells in each medium.

\begin{tabular}{|c|c|c|c|}
\hline \multirow{2}{*}{ Parameters } & \multicolumn{3}{|c|}{ Range and levels (coded) } \\
\hline & -1 & 0 & +1 \\
\hline Rice bran concentration (g.L $\left.\mathrm{L}^{-1}\right)$ & 2.5 & 5 & 7.5 \\
\hline Cell concentration (g. $\left.\mathrm{L}^{-1}\right)$ & 1 & 3 & 5 \\
\hline Media & & $\begin{array}{c}\text { Rice bran } \\
\text { concentration }\left(\mathrm{g} . \mathrm{L}^{-1}\right)\end{array}$ & $\begin{array}{c}\text { Cell } \\
\text { concentration }\left(\mathrm{g} . \mathrm{L}^{-1}\right)\end{array}$ \\
\hline 1 & & -1 & -1 \\
\hline 2 & & +1 & -1 \\
\hline 3 & & -1 & +1 \\
\hline 4 & & +1 & +1 \\
\hline 5 & & 0 & 0 \\
\hline 6 & & 0 & 0 \\
\hline
\end{tabular}




\subsection{Determination of acetic acid, cellobiose, ethanol, glucose, and glycerol}

The samples resulting from the fermentations media were filtered on cellulose acetate membrane. The aliquots were diluted and analyzed using the following conditions: Supelco Analytical C-610H column, maintained at $45^{\circ} \mathrm{C}$; volume of injection of $20 \mu \mathrm{L}$; refractive index detector RID 10-A; $5 \mathrm{mM} \mathrm{H}_{2} \mathrm{SO}_{4}$ as mobile phase and eluent, with a flow of $0.6 \mathrm{~mL} / \mathrm{min}$.

The ethanol yield based on the substrate consumption, $Y_{p / s}\left(\mathrm{~g} . \mathrm{g}^{-1}\right)$, and the volumetric productivity, $Q_{p}\left(\mathrm{~g} \cdot \mathrm{L}^{-1} \cdot \mathrm{h}^{-1}\right)$, were calculated by Equations 3 and 4, respectively:

$$
\begin{gathered}
Y_{p / s}=\frac{P-P_{0}}{S_{0}-S} \\
Q_{p}=\frac{P-P_{0}}{t}
\end{gathered}
$$

Where $P$ is the ethanol concentration at a specific time (g. $\left.\mathrm{L}^{-1}\right), P_{0}$ is the initial ethanol concentration $\left(\right.$ g. $\left.\mathrm{L}^{-1}\right), S$ is the glucose concentration at a specific time $\left(\mathrm{g} . \mathrm{L}^{-1}\right), S_{0}$ is the Initial glucose concentration (g. $\left.\mathrm{L}^{-1}\right)$ and $t$ is the time.

\section{RESULTS AND DISCUSSION}

\subsection{Batch fermentation}

The fermentation media were monitored for $72 \mathrm{~h}$ and the parameters cell concentration (g.L $\left.\mathrm{L}^{-1}\right)-$ obtained by the dry weight curve $\left(\mathrm{R}^{2}>0.99\right)$-, ethanol concentration $\left(\mathrm{g} . \mathrm{L}^{-1}\right), Y_{p / s}\left(\mathrm{~g} . \mathrm{g}^{-1}\right)$ and $Q_{p}\left(\mathrm{~g} \cdot \mathrm{L}^{-1} \cdot \mathrm{h}^{-1}\right)$, measured at regular intervals of $12 \mathrm{~h}$. The obtained data are shown in Table 2. For all fermentation media, glucose consumption was greater than or equal to $73 \%$. In general, fermentation medium $2\left(1 \mathrm{~g} . \mathrm{L}^{-1}\right.$ of cell and $7.5 \mathrm{~g} . \mathrm{L}^{-1}$ of rice bran) presented higher values of $Y_{p / s}$ and $Q_{p}$ when compared to the other media. Moreover, the higher values of substrate conversion in product and volumetric production rate were observed for 12 hours, when compared to the other times.

The presence of cellobiose was observed and remained constant and equal to 5 g. $\mathrm{L}^{-1}$ throughout the fermentation process for all the fermentation media, not being consumed by the microorganism. This sugar was possibly obtained by the partial hydrolysis of cellulose present in the rice bran (Sakimoto et al., 2017) and was also observed by Arokiasamy et al. (2016).
The production of glycerol was also observed in all the fermentation media elapsed $12 \mathrm{~h}$ of the process, being the greatest quantity obtained for the medium 4 , in which there was the addition of 7.5 g.L. $\mathrm{L}^{-1}$ of the rice bran extract. The presence of acetic acid was considered insignificant since all the obtained values were below 0.5 g. $\mathrm{L}^{-1}$ and did not interfere with the yield of the fermentation. Previous articles have shown that only for concentrations above 5 g.L. $\mathrm{L}^{-1}$ (Hoyer et al., 2013) the presence of this compound may cause inhibitory effect, reducing $Y_{p / s}$ and consequently $Q_{p}$.

Fermentation medium 2, which contained 7.5 g.L $\mathrm{L}^{-1}$ of rice bran and 1 g.L. $\mathrm{L}^{-1}$ of cells, had the highest concentration of ethanol after $12 \mathrm{~h}$ of fermentation (23.320 g. $\left.\mathrm{L}^{-1}\right)$, consuming $85 \%$ of the present glucose, and a mean of 18.337 g. $\mathrm{L}^{-1}$, considering $72 \mathrm{~h}$ of the process. For medium 3, consisting of 2.5 g.L. $\mathrm{L}^{-1}$ and 5 g. $\mathrm{L}^{-1}$ of rice bran and cells, respectively, the obtained values were 21.060 g.L. $\mathrm{L}^{-1}$ of ethanol after $12 \mathrm{~h}$ and a glucose consumption of $85 \%$, in addition to an average of 18.975 g.L.- $\mathrm{L}^{-1}$, considering $72 \mathrm{~h}$ after the beginning of the fermentation. The obtained value was higher than that observed in the study developed by Arokiasamy et al. (2016), where the maximum concentration of obtained ethanol was 12.5 g. $\mathrm{L}^{-1}$, using the same yeast and substrate of this study, after 48 hours of fermentation. For all the fermentation media, the ethanol concentration starts to drop from 12 hours of fermentation on. This fact can be justified either via the ethanol consumption by the yeast itself when the substrate concentration was low (Silva et al., 2011), or the ethanol evaporation, phenomenon also observed by Siepmann et al.(2018) after 12 hours of fermentation.

The profiles of glucose, ethanol production, and cellular concentration during the fermentations for the media 2 and 4, which presented the highest and lowest mean of $Y_{p / s}\left(0.44,0.26 \mathrm{~g} . \mathrm{g}^{-1}\right)$ and $Q_{p}\left(0.56,0.34 \mathrm{~g} . \mathrm{L}^{-1} \cdot \mathrm{h}^{-1}\right)$, respectively, are shown in Figure 1. Similar values were obtained by Favaro et al. (2017), who evaluated the fermentative process of rice bran with two wild $S$. cerevisiae strains and obtained a mean of 0.475 for $Y_{p / s^{*}}$. Glucose consumption as well as cell growth showed similar behavior for both media. A high affinity of the microorganism was observed with the substrate since its consumption was approximately $89 \%$ in the first 12 hours of fermentation. For the fermentation medium 2 , where there was a higher concentration of 


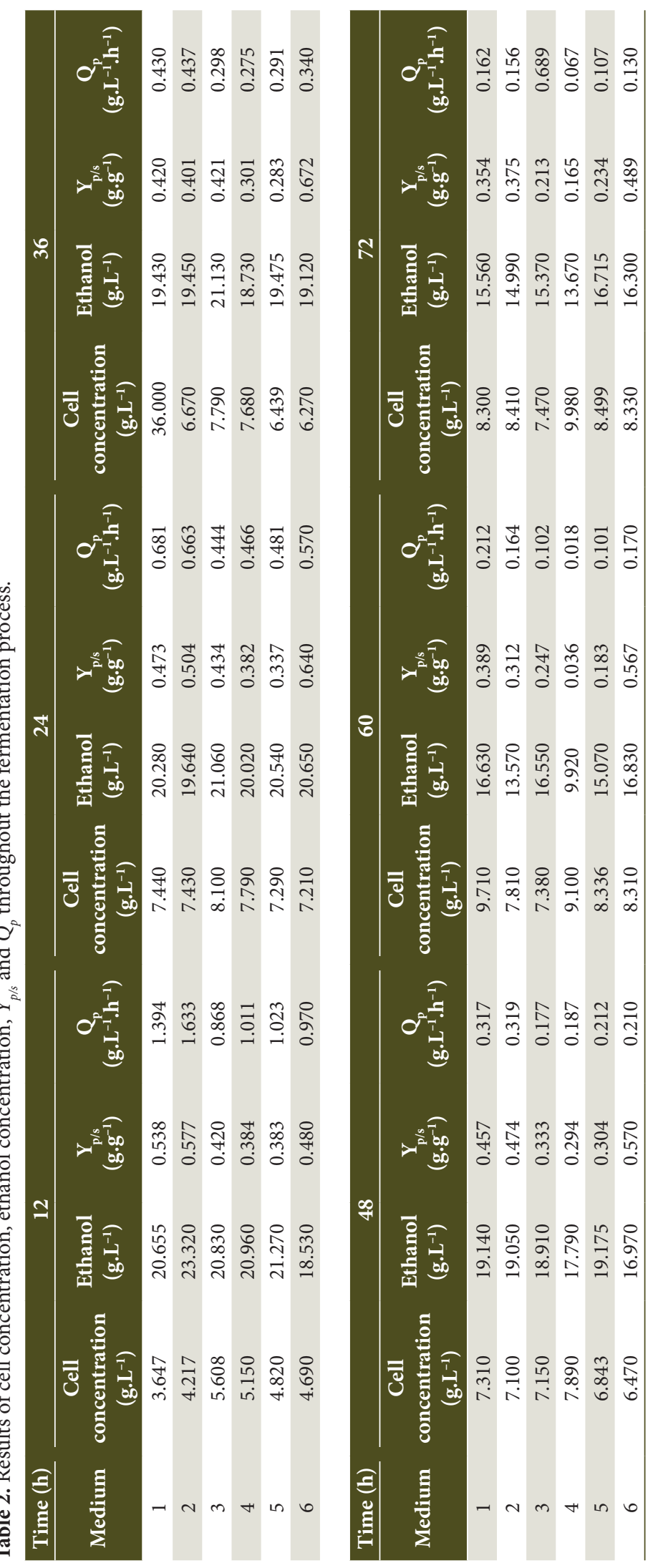


substrate per cell amount (40 and 1 g. $\mathrm{L}^{-1}$, respectively), a greater development of the microorganism was observed, reaching a cellular concentration higher than the fermentation medium 4 . For this reason, the medium also shows a higher ethanol production, since there was enough nutrient for its development and later its conversion into the product of interest, having its highest concentration for 12 hours.

\subsection{Statistical analysis}

The Pareto graph was used to evaluate the influence of the factors. At $t=12$ hours, the addition of rice bran and modification of the initial cell concentration of the medium does not significantly influence $Y_{p / s}$ (Figure 2a), since this factor presents a value of $\mathrm{p}>0.05$, remaining on the left of the vertical line of significance $(p=0.05)$. This fact is due to the preference of the yeast to the consumption of the glucose rather than the nutrients provided by the rice bran (Silva et al., 2011).

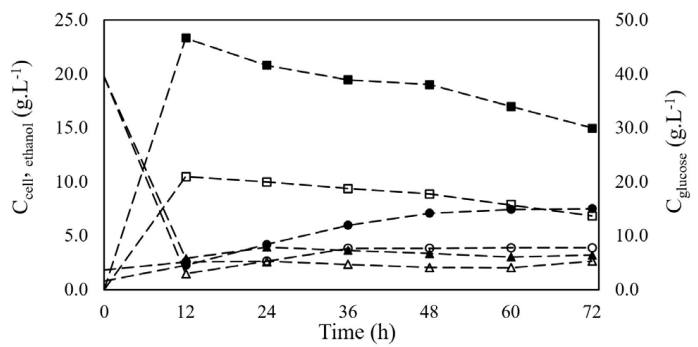

Figure 1. Concentration profiles of cell $(\bullet, 0)$, ethanol $(\boldsymbol{\bullet}, \square)$, and glucose $(\boldsymbol{\Lambda}, \Delta)$ throughout the fermentation process for media 2 and 4 , respectively.

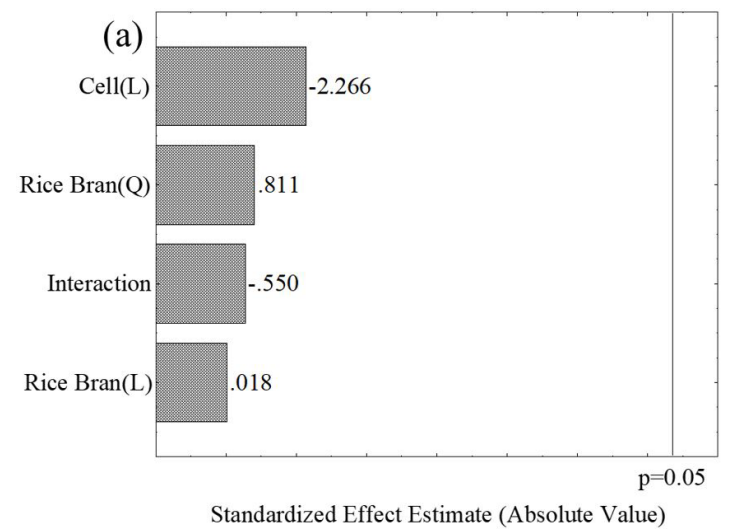

At $t=72$ hours (Figure 2b), it can be observed that the linear term of the cellular concentration (Cell(L)), the quadratic term of the rice bran concentration (Rice Bran (Q)), and the linear interaction of these two factors (Interaction) showed statistically significant effects for $Y_{p / s}$. The linear term of the rice bran concentration (Rice Bran (L)) did not present a statistically significant effect.

The effect of these factors can also be observed through the response surface graph and the contour plot shown in Figure 3. The value of $Y_{p / s}$ has a linear behavior along the $y$ axis (cellular concentration), the same behavior pointed to this factor by the pareto graph. As the initial cell concentration is increased the $Y_{p / s}$ value decreases for any rice bran concentration. On the other hand, for the $\mathrm{x}$-axis, the increase of the rice bran concentration causes a quadratic effect in the value of $Y_{p / s}$.

For the present study the highest ethanol yield was obtained at the factorial point of maximum for the rice bran concentration and the minimum point for the cellular concentration, 7.5 and 1 g.L. $\mathrm{L}^{-1}$, respectively, obtaining an $Y_{p / s}$ of $0.375 \mathrm{~g} \cdot \mathrm{g}^{-1}$. The lower cellular concentration favors a higher $Y_{p / s}$, since higher cells concentration in the medium generates a high consumption of substrate used only for its growth and not the ethanol production.

\subsection{Kinetic parameters obtained for the fermentation process}

The kinetic parameters were evaluated for the six fermentation media (Table 3 ) being the correlation coefficient considered satisfactory for all cases,

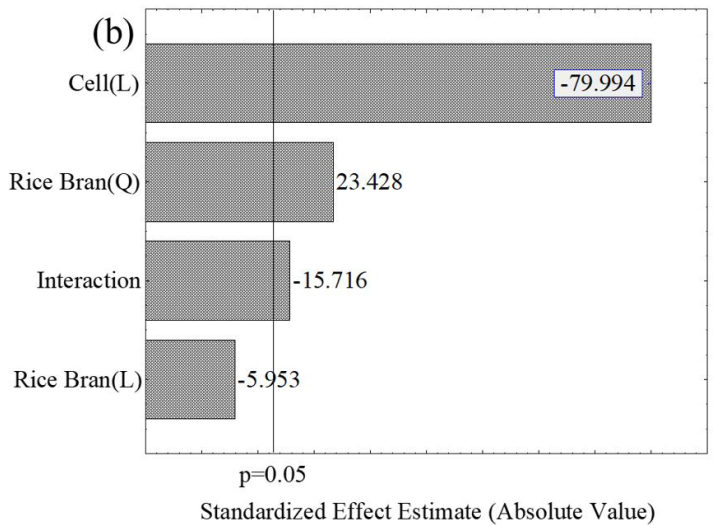

Figure 2. Pareto chart used to evaluate the influence of the factors at 12 hours (a) and 72 hours (b). 


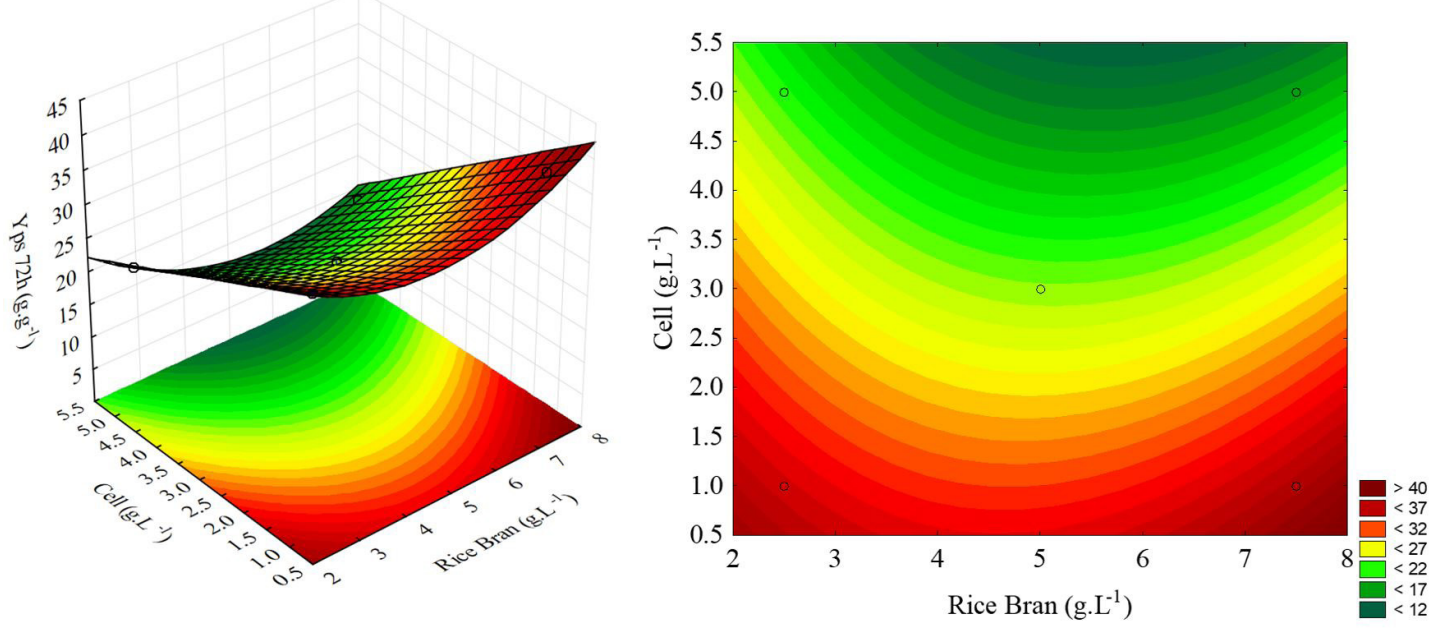

Figure 3. 3D surface and contour plot for interaction effects for $Y_{p / s}$, respectively, at $t=72$ hours.

Table 3. Kinetic parameters obtained for the fermentation process.

\begin{tabular}{cccc}
$\begin{array}{c}\text { Fermentation } \\
\text { media }\end{array}$ & $\boldsymbol{\mu}_{\max }\left(\mathbf{h}^{-1}\right)$ & $\mathbf{K}_{\mathbf{s}}\left(\mathbf{g} \cdot \mathbf{L}^{-1}\right)$ & $\mathbf{R}^{2}$ \\
\hline 1 & 0.0248 & 21.736 & 0.970 \\
2 & 0.0542 & 24.005 & 0.950 \\
3 & 0.0012 & 4.434 & 0.966 \\
4 & 0.1046 & 32.427 & 0.955 \\
5 & 0.1046 & 23.451 & 0.980 \\
6 & 0.0670 & 8.632 & 0.822 \\
\hline
\end{tabular}

which guarantees a good fit of the model chosen and therefore, greater reliability in the obtained results. The highest affinity for the substrate was observed in medium 4 , as a higher value of $K_{s}\left(32.427\right.$ g.L.- $\left.\mathrm{L}^{-1}\right)$ was obtained. Fermentation media 1,2 , and 5 showed similar affinities to the substrate since the values obtained for the Monod's constant were similar and close to $22 \mathrm{~g} . \mathrm{L}^{-1}$. The fermentation medium 3 had the lowest $\mu_{\max }\left(0.0012 \mathrm{~h}^{-1}\right)$ and consequently the lowest $K_{s}\left(4.434\right.$ g.L $\left.\mathrm{L}^{-1}\right)$. During the fermentation process the microorganism can either use the substrate for its growth or to convert it into a metabolite of interest. The fact that the third fermentation medium has the highest ethanol concentration, associated with a lower maximum growth observed by the kinetic study, corroborates the fact that this condition is conducive to the ethanol production since this phenomenon overcame the microorganism growth.

\section{CONCLUSION}

Nutritional supplementation in the fermentation process was considered to be a determinant factor for the ethanol biotechnological production, since it has proved to be significant and with potential to increase its production. Using a factorial analysis $2^{2}$ it was possible to infer that the nutrient source arranged by the rice bran affects the ethanol yield response in the studied range in a quadratic form, and its linear form showed no significant effect. Furthermore, the initial cell concentration of the medium showed significant effect in its linear form, showing that the choice of lower cell concentrations increases the yield of final ethanol as its growth does not exceed the production of the product of interest.

For $t=12$ hours and 72 hours the maximum $Y_{p / s}$ (0.577 g. $\mathrm{g}^{-1}$ and $0.375 \mathrm{~g} . \mathrm{g}^{-1}$, respectively) was observed at the point of maximum concentration of rice bran and minimum cell concentration, represented by medium 2. It was observed a higher $\mu_{\max }\left(0.1046 \mathrm{~h}^{-1}\right)$ and $K_{s}\left(32.427\right.$ g.L $\left.\mathrm{L}^{-1}\right)$ in the fermentation medium 4.

\section{ACKNOWLEDGEMENTS}

The authors thank the technicians from the laboratories of Instrumental Analysis (Thais Monique) and Biological Sciences (Paloma Gonçalves) of PUC Minas. 


\section{SUBMISSION STATUS}

Received: 5 nov., 2018

Accepted: 13 dec., 2018

\section{CORRESPONDENCE TO}

\section{Victor Rezende Moreira}

Departamento de Engenharia Química, Pontifícia Universidade Católica de Minas Gerais - PUC-MG, Av. Dom José Gaspar, 500, CEP 30535-901, Belo Horizonte, MG, Brasil e-mail: victorrznde.eng@gmail.com

\section{FINANCIAL SUPPORT}

This research was funded by Coordination of Superior Level Staff Improvement (CAPES); National Council for Scientific and Technological Development (CNPq); Foundation for Research Support of the State of Minas Gerais (FAPEMIG); and Pontifical Catholic University of Minas Gerais (PUC Minas).

\section{REFERENCES}

Arenas-Cárdenas P, López-López A, Moeller-Chávez GE, León-Becerril E. Current pretreatments of lignocellulosic residues in the production of bioethanol. Waste and Biomass Valorization 2017; 8(1): 161-181. http://dx.doi. org/10.1007/s12649-016-9559-4.

Arokiasamy WJ, Xavier VAJ, Sivasankaran C, Ramanujam PK, Alagurajan S, Rajkumar R. Simultaneous saccharification and fermentation of rice bran and ground nut shell for the production of ethanol. J. Chem. Pharm. Sci. 2016; 9: 202-205.

Azhar SHM, Abdulla R, Jambo SA, Marbawi H, Gansau JA, Faik AAM, Rodrigues KF. Yeasts in sustainable bioethanol production: a review. Biochemistry and Biophysics Reports 2017; 10: 52-61. https://doi.org/10.1016/j.bbrep.2017.03.003.

Favaro L, Cagnin L, Basaglia M, Pizzocchero V, van Zyl WH, Casella S. Production of bioethanol from multiple waste streams of rice milling. Bioresource Technology 2017; 244(Pt 1): 151-159. http://dx.doi.org/10.1016/j. biortech.2017.07.108. PMid:28779666.

Fogler HS. Elements of chemical reaction engineering. $3^{\text {rd }}$ ed. New Jersey: Prentice-Hall International, Inc.; 2009.

Guo M, Song W, Buhain J. Bioenergy and biofuels: history, status, and perspective. Renewable \& Sustainable Energy
Reviews 2015; 42: 712-725. http://dx.doi.org/10.1016/j. rser.2014.10.013.

Hoyer K, Galbe M, Zacchi G. Influence of fiber degradation and concentration of fermentable sugars on simultaneous saccharification and fermentation of high-solids spruce slurry to ethanol. Biotechnology for Biofuels 2013; 6(1): 145 . http://dx.doi.org/10.1186/1754-6834-6-145. PMid:24103097.

Lerkkasemsan N, Lee WC. Study of ethanol fermentation reaction using Saccharomyces diastaticus in a two-tank fermentation system with cell recycling. Journal of the Taiwan Institute of Chemical Engineers 2018; 86-96. https:// doi.org/10.1016/j.jtice.2018.06.001.

Mohd Azhar SH, Abdulla R, Jambo SA, Marbawi H, Gansau JA, Mohd Faik AA et al. Yeasts in sustainable bioethanol production: a review. Biochemistry and Biophysics Reports 2017; 10: 52-61. http://dx.doi.org/10.1016/j. bbrep.2017.03.003. PMid:29114570.

Monod J. The growth of bacterial cultures. Annual Review of Microbiology 1949; 3(1): 371-394. http://dx.doi. org/10.1146/annurev.mi.03.100149.002103.

Papapetridis I, Goudriaan M, Vázquez Vitali M, de Keijzer NA, van den Broek M, van Maris AJA et al. Optimizing anaerobic growth rate and fermentation kinetics in Saccharomyces cerevisiae strains expressing Calvin-cycle enzymes for improved ethanol yield. Biotechnology for Biofuels 2018; 11(1): 17. http://dx.doi.org/10.1186/s13068017-1001-z. PMid:29416562.

Sakimoto K, Kanna M, Matsumura Y. Kinetic model of cellulose degradation using simultaneous saccharification and fermentation. Biomass and Bioenergy 2017; 99: 116121. http://dx.doi.org/10.1016/j.biombioe.2017.02.016.

Sharma HK, Chunbao X, Wensheng Q. Biological pretreatment of lignocellulosic biomass for biofuels and bioproducts: an overview. Waste and Biomass Valorization 2017; 10(2): 235-251

Siepmann FB, Canan C, Jesus MMM, Pazuch CM, Colla E. Release optimization of fermentable sugars from defatted rice bran for bioethanol production. Acta Scientiarum. Technology 2018; 40(1): e35000. http://dx.doi.org/10.4025/ actascitechnol.v40i1.35000.

Silva VF, Arruda PV, Felipe MG, Gonçalves AR, Rocha GJ. Fermentation of cellulosic hydrolysates obtained by enzymatic saccharification of sugarcane bagasse pretreated by hydrothermal processing. Journal of Industrial Microbiology \& Biotechnology 2011; 38(7): 809-817. http:// dx.doi.org/10.1007/s10295-010-0815-5. PMid:20740373.

Zabed H, Sahu JN, Suely A, Boyce AN, Faruq G. Bioethanol production from renewable sources: current perspectives and technological progress. Renewable \& Sustainable Energy Reviews 2017; 71: 475-501. http://dx.doi.org/10.1016/j. rser.2016.12.076. 